\title{
1. INTRODUCCIÓN
}

Es ya un tópico señalar que la población latinoamericana es mayoritariamente urbana y, consiguientemente, enfatizar la centralidad de las ciudades como escenarios donde se llevan a cabo la mayor parte de las actividades económicas, politicas y culturales. El interés por lo urbano entre los científicos sociales latinoamericanos posee ya una importante trayectoria que ba pasado a ocupar un lugar propio dentro de la sociología urbana en general. La década de 1980 se abría en el campo de lo urbano con una sensación de profunda crisis. Los paradigmas existentes parecian insuficientes para dar respuesta a las nuevas situaciones. Los esquemas explicativos que renovaron la disciplina en la década de 1970 parecieron perder solidez, asistiéndose a una diversidad, tanto en cuanto a las temáticas de estudio como a los referentes teóricos utilizados. Es en este contexto en el que las nuevas realidades y experiencias latinoamericanas y las reflexiones a que dieron lugar las mismas contribuyeron a generar una renovación en el marco de la sociología urbana.

En concreto, América Latina ha contribuido a generar inquietudes por temas como la urbanización popular, la vivienda, la ecología, la acción politica del Estado en relación problemas urbanos, los movimientos sociales urbanos y la organización popular, los procesos de descentralización o la influencia del sector informal de la economía en la configuración urbana. La crisis de paradigmas ba suscitado una nueva preocupación por la definición de lo urbano, planteándose si realmente podría bablarse de un campo exclusivo de análisis para la sociología urbana.

Con este número de América Latina Hoy, coordinado por Marisa Ramos, Javier Garrido y Flavia Freidenberg, hemos querido hacernos eco de estas inquietudes. Con ese fin, pretendemos ofrecer una visión de conjunto de la realidad actual de las grandes ciudades latinoamericanas y de las reflexiones que sobre ellas se están planteando. Por ello, abordamos la situación urbana desde diversos puntos de vista que tratan diferentes aspectos de una misma realidad, desde la ubicación de las ciudades latinoamericanas en un contexto marcado por la globalización y la crisis, a los análisis sobre las posibilidades de intervención politica en las mismas y de democratización de los poderes locales; desde las reflexiones sobre los centros bistóricos latinoamericanos a las nuevas formas de pensar lo urbano en América Latina; desde las experiencias de organización popular a las estrategias de construcción de viviendas. Con esta selección de reflexiones sobre la ciudad, esperamos contribuir a redescubrir la potencialidad de las ciudades como escenarios de las iniciativas políticas, económicas y sociales que se vislumbran en América Latina. 


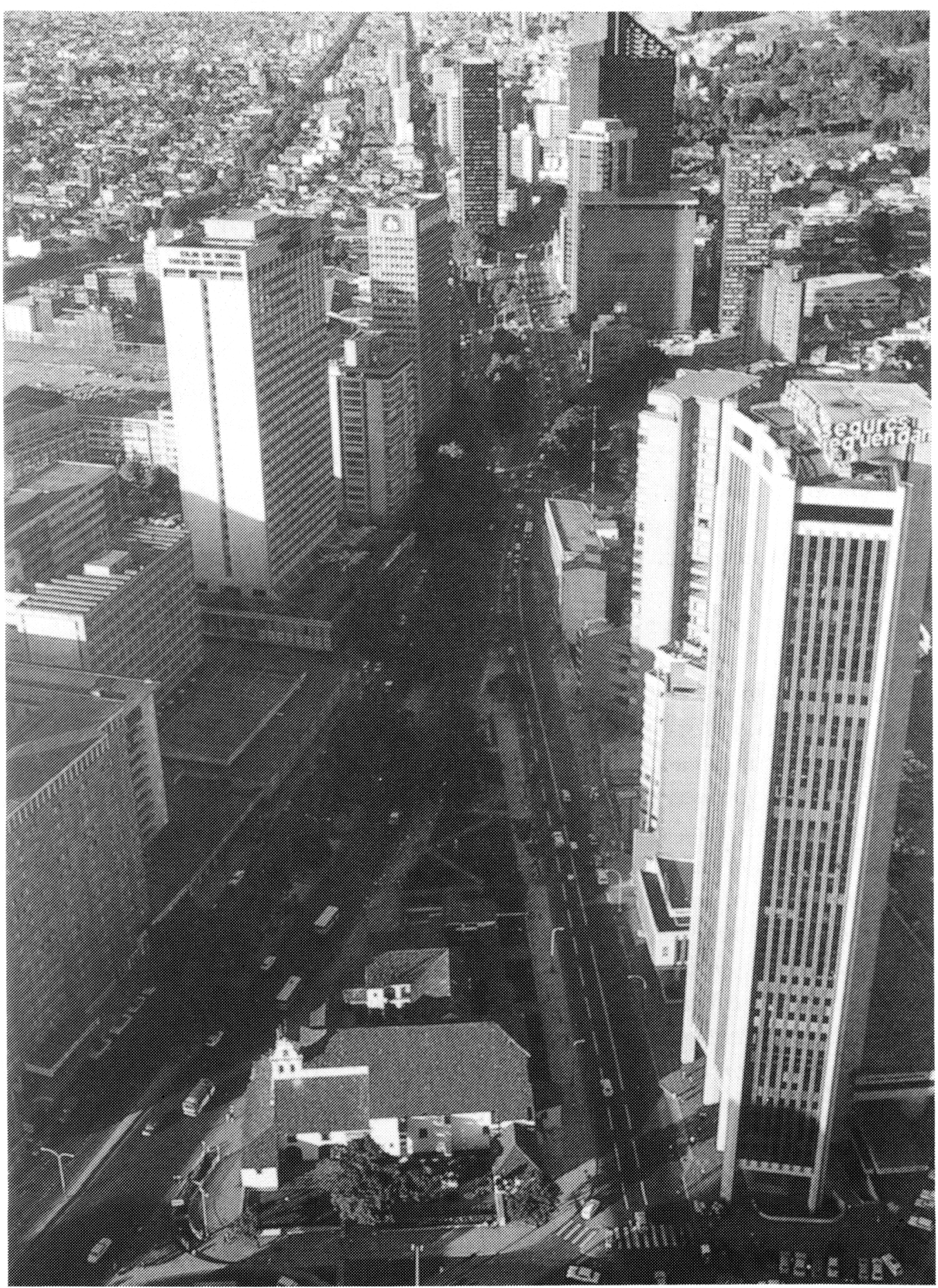

